\title{
Equilibrium Condition during Locomotion and Gait in Broiler Chickens
}

\section{-Author(s)}

\author{
Alves $\mathrm{MCF}^{\mathrm{I}}$ \\ Almeida Paz ICL" \\ Nääs IA IV \\ Garcia RGIV \\ Caldara FRIV \\ Baldo GAA" \\ Nascimento $\mathrm{GR}^{\prime}$ \\ Amadori MS ${ }^{\mathrm{IV}}$ \\ Felix GA ${ }^{\text {III }}$ \\ Garcia EA" \\ Molino AR"
}

Faculdade de Ciências Agrárias - FCA, Universidade Estadual de Maringá - UEM, Maringá, Paraná, Brazil

" Faculdade de Medicina Veterinária e Zootecnia - FMVZ, Universidade Estadual Paulista "Júlio de Mesquita Filho" - UNESP, Botucatu, São Paulo, Brazil

III Faculdade de Veterinária e Zootecnia - FVZ, Universidade Federal de Goiás - UFG, Goiânia, Goiás, Brazil

Iv Faculdade de Ciências Agrárias - FCA, Universidade Federal da Grande Dourados - UFGD, Dourados, Mato Grosso do Sul, 79.804-970, Brazil

\section{-Mail Address}

Corresponding author e-mail address Marília Carvalho Figueiredo Alves Rua Ceará, 295

87033300. Maringá, Paraná, Brazil Tel: $\quad$ +55 (44) 9708-5284

Email: marilia.mcfa@yahoo.com.br

\section{- Keywords}

Angulation, bone pathologies, broiler production, locomotion problems, posture, production
welfare.

\section{ABSTRACT}

The experiment was carried out with the objective of evaluating a methodology to estimate the angulation and equilibrium condition, relating them to gait score and the main diseases of the locomotion system in males and females of commercial broiler strains. A completely randomized experimental design in a factorial arrangement $(2 \times 2)$ was applied, consisting of two sexes and two genetic strains, with five replicates of 53 chickens each. The following characteristics related to broiler locomotion were studied: gait score (GS); incidence of Valgus (VAL) and Varus (VAR) deformities and of pododermatitis (POD); body angle relative the ground ( $A N G$ ); equilibrium condition ( $E C$ ); body weight (BW) and breast weight (BrW); and incidence of femoral degeneration (FD), tibial dyschondroplasia (TD) and spondylolisthesis (SPO). GS, and VAL and VAR were assessed inside a broiler house. Birds were then photographed to estimate ANG and EC. Birds were sacrificed at 42 days of age and analyzed for FD, TD, and SPO. Breast percentage was not influenced by sex or strain. Males showed better ANG than females, regardless of strain. Overall, the strains studied showed prostrated EC. The correlation between GS and the evaluated traits was low. There was a moderate to high association between EC and ANG both in males and females. GS showed low correlation with locomotion problems, and therefore, it is a poor indicator of skeletal diseases. On the other hand, the moderate to high correlations of ANG and EC with locomotion problems make them better indicators of bone diseases than gait score, which is possibly more related to EC and body posture than to bone pathologies.

\section{INTRODUCTION}

Chicken meat production has experienced exponential growth in the international market, and this is the result of intensive rearing based on proper nutrition, environmental and health management, and genetic improvement, with the development of more efficient strains for weight gain. However, production dropped last year due to the rise in the prices of corn and soybean, which are the main feedstuffs of broiler diets, but it is believed that the industry has again found its balance in 2014 (ABPA, 2014).

One of the consequences of the growth of the poultry industry is the increase in the demands of the consumer markets worldwide in terms of food quality and safety standards, as well as environmental preservation and animal welfare (Nääs, 2008). Therefore, higher productivity needs to be aligned with animal welfare and environmental sustainability.

Another significant factor that may cause broiler production losses is the emergence of bone diseases that affect broilers with rapid muscle development during the first weeks of life. Their bone structure is unable to maintain the same growth rate as the muscles, and this imbalance 
Alves MCF, Almeida Paz ICL, Nääs IA, Garcia RG, Caldara FR, Baldo GAA, Nascimento GR, Amadori MS, Felix GA, Garcia EA, Molino AR
Equilibrium Condition during Locomotion and Gait in Broiler Chickens overloads the entire bone structure of these chickens, resulting in deformities (Julian, 1984; Goliomytis et al., 2003; Almeida Paz et al., 2005). Leg disorders in broilers are an important economic issue in the poultry industry due to the heavy losses resulting from carcass downgrading and condemnations (Waldenstedt, 2006).

A previous study reported that the welfare of chickens suffering diseases and injuries is negatively affected (Broom \& Molento, 2004). When exposed to stress from diseases or prolonged distress when experiencing negative rearing conditions, broilers tend to present low weight gain and poor body development, which may lead to death (Knowles \& Broom, 1990). Amongst the several factors that negatively influence broiler welfare, the incidence of locomotor problems is highlighted, particularly in intensively-reared broilers (Almeida Paz, 2008).

The high weight gain and the rapid growth of the breast muscle of current broiler strains may influence their body stance. Almeida Paz et al. (2010) reported that broilers with heavy breasts remain prostrated and leaning towards the ground. Consequently, the equilibrium condition and the angulation of these birds are affected, inducing discomfort while walking, deteriorating their welfare, and resulting in a higher number of lightweight birds at the end of the growout period because they are unable to move, and therefore, to reach the feeders and the drinkers.

Several studies suggest techniques to evaluate locomotion disorders in broiler chickens, and gait score is the most frequently method applied to assess broilers walking conditions (Kestin et al., 1992; Cordeiro et al., 2009; Almeida Paz et al., 2010). This approach evaluates how broilers walk along a one-meter linear path, attributing a score according to the locomotion performance (Fernandes et al., 2012). However, this methodology does not include the evaluation of the bird posture/stance. One methodology often used in humans to evaluate the equilibrium condition, center of gravity, balance oscillation, and angulation is biophotogrammetry. This technology is simple and noninvasive and may be used to assess the body angulation and equilibrium condition of broilers.

Most methodologies employed in humans cannot be used to perform this type of study in poultry, as the evaluated subject must understand the process to follow the applied methodology correctly. However, by adapting the photogrammetry method used by physiotherapists by the use of captured images of broilers in profile and considering them as a geometric figure (a spherical cap), it is possible, using mathematical equations, to determine the center of gravity of the cap and its axis of symmetry. Based on these values, the equilibrium condition and angulation of birds during the stance can be estimated.

This experiment was carried out with the objective of developing and evaluating a methodology to estimate the angulation and equilibrium condition during the stance phase, and associating them with gait score and the main diseases of the locomotion system in male and female of commercial broiler strains.

\section{MATERIALS AND METHODS}

The experiment was conducted at the poultry production sector of the Federal University of Grande Dourados, located in the county of Dourados (MS), Brazil, using 1,060 sexed one-day-old chicks. The study was approved by the Ethics Committee of UFGD under protocol 009/2012.

A completely randomized experimental design in a factorial arrangement $(2 \times 2)$ was applied, and the treatments consisted of two sexes (male or female) and two commercial strains (Cobb®500 or Ross $® 308)$, with five replicates of 53 chickens each. The birds were randomly distributed in 20 pens with $4.5 \mathrm{~m}^{2}$ of floor area, at a population density of $11.77 \mathrm{birds} / \mathrm{m}^{2}$. Feed and water were provided ad libitum.

The following pathologies and conditions were evaluated: gait score (GS), Valgus (VAL) and Varus (VAR) deformities, pododermatitis (POD), angulation (ANG), equilibrium condition (EC), body weight (BW), breast weight (BrW), femoral degeneration (FD), tibial dyschondroplasia (TD), and spondylolisthesis (SPO).

\section{Gait score and locomotion disorders}

The gait score of all 1,060 individuals was evaluated inside the experimental house when broilers were 40 days of age. The evaluation was based on a scoring system developed by Kestin et al. (1992), and which is used to evaluate lameness in broilers. The chickens were induced to walk for a distance of $1 \mathrm{~m}$ on a flat surface containing rice husks, simulating the broiler litter conditions found in the broiler house. The methodology consisted of subjective observations that allowed attributing a score on how the bird walked. A six-point scale was used to classify gait score, ranging from 0 to 5 . Score 0 was given to healthy birds that showed no gait abnormalities; score 1 to birds that showed slight gait difficulties; score 2 to birds showing easily identifiable and defined gait difficulties; score 3 to birds with slight difficulties, easily identifiable through observation and that interfered with locomotion; score 
Alves MCF, Almeida Paz ICL, Nääs IA, Garcia RG, Caldara FR, Baldo GAA, Nascimento GR, Amadori MS, Felix GA, Garcia EA, Molino AR

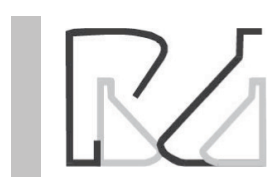

Equilibrium Condition during Locomotion and Gait in Broiler Chickens
4 to birds with severe locomotion problems, and that moved only when highly motivated; and score 5 to birds that were unable to move.

On the same occasion, VAL and VAR deformities were evaluated in 30 birds per treatment, according to the methodology described by Almeida Paz et al. (2010). The angle between the third digit and the tibia of the right and left legs was measured using a pachymeter and protractor. When the angle obtained was greater than 10 positive degrees, VAL was characterized; whenever the angle was greater than 10 negative degrees, VAR was characterized (Figure 1).

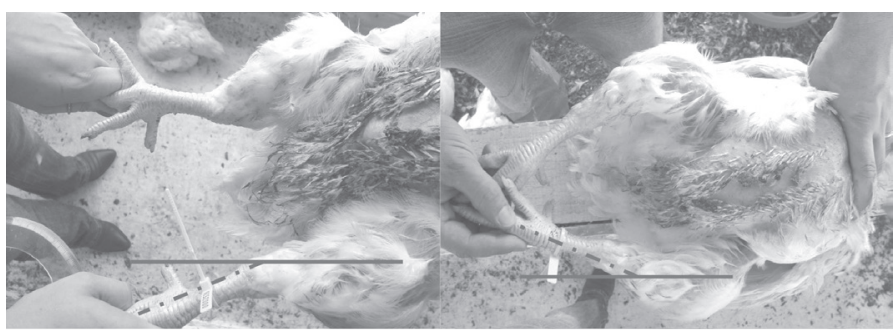

Figure 1 - Valgus and Varus deformities. In A: Valgus deformity, angle greater than 10 positives degrees. In B: Varus deformity, angle greater than 10 negative degrees.

Subsequently, the birds' feet were evaluated. The evaluation consisted of analyzing footpad lesions (Figure 2), attributing scores from 0 to $2(0=$ intact footpad, $1=$ initial lesion with a diameter up to $5 \mathrm{~mm}$, causing intermediate discomfort, and 2 = extensive lesion, diameter higher than $5 \mathrm{~mm}$, causing clear discomfort, and consequently, reduced welfare), according to the methodology described by Almeida Paz et al. (2010).
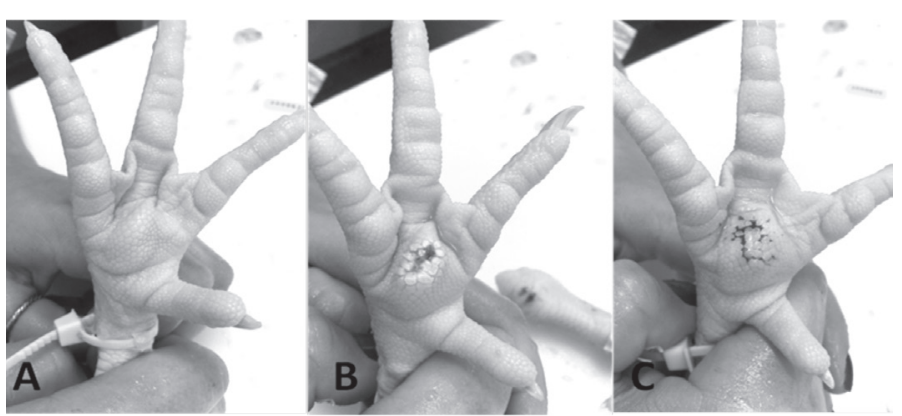

Figure 2 - Macroscopic evaluation of footpad dermatitis. A - intact footpad; B- Initial lesion of up to $5 \mathrm{~mm}$ in diameter, and C- severe lesions with more than $5 \mathrm{~mm}$ in diameter.

At 42 days of age, the same birds that were photographed on day 40 were weighed and transported to the Meat Technology Laboratory of that same institution. Broilers were stunned and then bled by cutting the jugular vein and the carotid artery. Breast yield was calculated as the percentage of breast weight relative to carcass weight.

Femoral degenaration (FD) was assessed by analyzing the integrity of the femoral head of the left and right legs, attributing scores from 0 to 2 ( 0 = intact femoral head, no cartilage lesion; 1 = partial integrity of the cartilage that surrounds the femoral head, which may cause discomfort to the bird, and $2=$ absence of cartilage, the bone is injured, causing discomfort to the bird, which may be unable to walk, negatively affecting its welfare), as described by Almeida Paz et al. (2010).

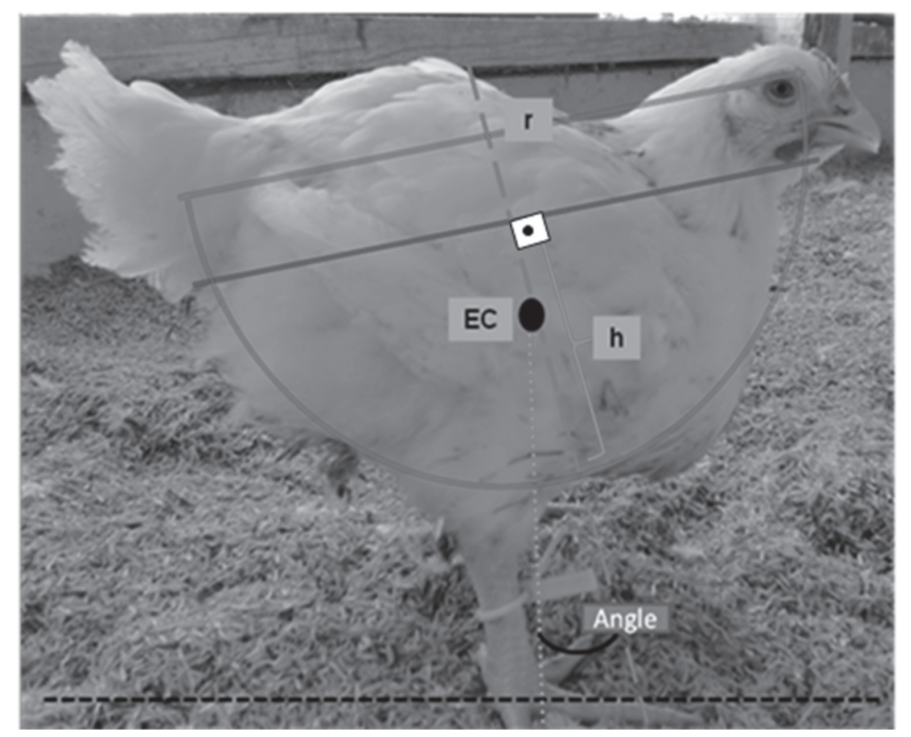

Figure 3 - Estimation of the equilibrium condition $(E C)$ and the angle of postural characteristics (ANG) of broilers, showing the radius ( $r$ ); a line was drawn parallel to the radius of the cap (blue line); the sagitta (h) of the cap was found; a line was drawn parallel to the ground (black dotted line); perpendicular line traced deteremined the center of gravity (green dotted line).

The analysis of TD consisted of macroscopically measuring the thickness of the growth cartilage in the tibia by making an incision in the left and right tibiae of each bird, exposing the growth plate (Figure 4). Scores between 0 and 2 were given (score $0=$ the bones show no thickening of the growth plate cartilage (absence of abnormal cartilage thickening); score $1=$ slightly abnormal thickening of the tibial growth plate cartilage -1 to $3 \mathrm{~mm}$; and score 2 = growth plate cartilage thicker than $3 \mathrm{~mm})$, as suggested by Almeida Paz (2008).

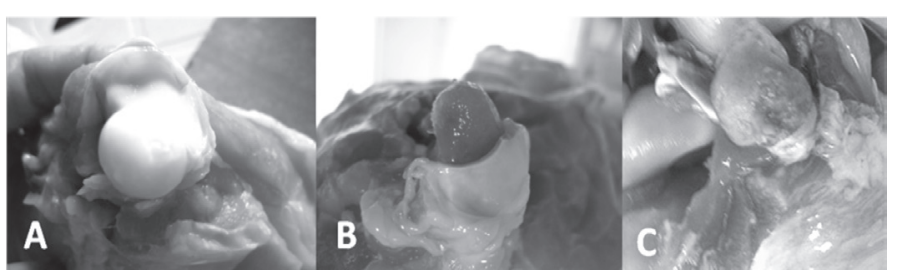

Figure 4 - Macroscopic evaluation of femoral degeneration. In A - score 0 , intact femoral head; B - score1, initial lesion, partial integrity of cartilage; and C - score 2, deep injury, absence of cartilage.

The incidence of SPO was evaluated by making a sagittal section in the back of the birds between the $6^{\text {th }}$ and $7^{\text {th }}$ thoracic vertebrae for the visual inspection of the spine (Paixão et al., 2007). When the axis of the 
Alves MCF, Almeida Paz ICL, Nääs IA, Garcia RG, Caldara FR, Baldo GAA, Nascimento GR, Amadori MS, Felix GA Garcia EA, Molino AR
Equilibrium Condition during Locomotion and Gait in Broiler Chickens vertebrae was normal and there was no spinal cord compression, a score of 0 was given (absence of spinal problems); when the thoracic vertebrae compressed the spinal cord, possibly hindering locomotion, a score of 1 was given (onset of spondylolisthesis).

\section{Equilibrium condition and Angulation}

The same birds used to evaluate VAL and VAR were used to record the images. Broilers were placed one meter away from the camera tripod to standardize the images, which were used to estimate ANG and EC. The profile photograph of the broiler (Figure 5) was considered as a geometric figure - that is, a spherical cap - and the circumference of that cap was traced around the image. The radius of the sphere was established, and it was constant for all analyzed figures to standardize all measurements, considering that the birds differed in size. Next, a line was drawn parallel to the radius of the cap, from the cloaca to the wattle. The sagitta of the cap was calculated as the difference between the radius of the cap and the parallel line, and varied according to bird size. The center of gravity of the cap was calculated according to the formula:

$$
C G=3 / 4(2(r-h) 2 / 3(r-h))
$$

where: $C G=$ center of gravity; $r=$ radius of the sphere; and $\mathrm{h}=$ sagitta.

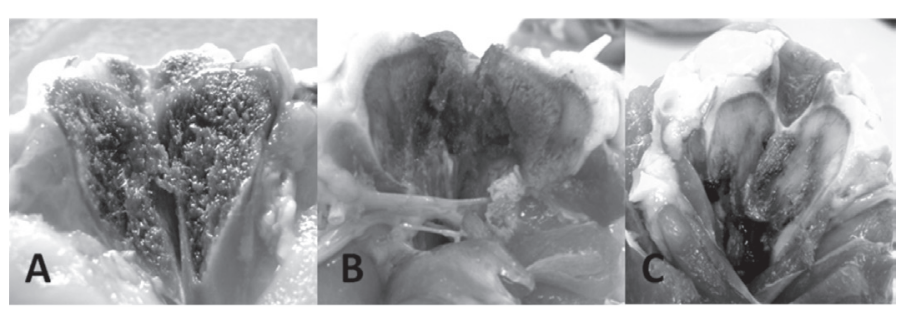

Figure 5 - Macroscopic evaluation of tibial dyschondroplasia. A - score 0, no thickening of the growth cartilage; B - score 1, abnormal thickening of the growth plate cartilage (range 1 to $3 \mathrm{~mm}$ ); and C - score 2, growth plate cartilage thicker than $3 \mathrm{~mm}$.

A line was drawn parallel to the ground at the base of the footpad, intersecting the perpendicular line traced from the center of gravity found in order to estimate the EC of the bird. A horizontal line was drawn at the base of the footpad, estimating the bird's EC to measure the ANG between the center of gravity and the ground. ANG was determined by the intersection between the axis of symmetry and the horizontal line, and scores given according to the location where this perpendicular line was located. When the perpendicular line was drawn in front of the footpad, the bird presented abnormal body posture, i.e., it leaned back and was extremely erect (score 1). Perfect equilibrium condition was attributed when the perpendicular line of the center of gravity fell on the area of the footpad (score 2). When the perpendicular line fell behind the footpad, the bird presented prostrated equilibrium condition, or a leaning forward posture (score 3). In addition, images of birds that could not stand were recorded (score 4) to associate EC with the other traits evaluated in the study.

From the intersection between the axis of symmetry of the spherical cap - a $90^{\circ}$ angle - and the perpendicular line of the center of gravity, the ANG of each bird was estimated, with the aid of a protractor, as the difference between the angle measured and the angle of the axis of symmetry. Birds that were unable to walk and lying down at the time the images were taken presented high GS and were attributed an ANG of $0^{\circ}$.

\section{Statistical analysis}

The results were analyzed using SAS 9.2 statistical software (2004). Data on locomotion problems (GS, VAL and VAR, POD, ANG, EC, FD, TD and SPO) were subjected to non-parametric statistical analysis, using the Kruskal-Wallis test to assess the normality of residuals, and Levene's test was applied to determine variance homogeneity. Data on body weight and breast weight were evaluated by analysis of variance (ANOVA) and means were compared by Tukey's test, at $5 \%$ significance level. Principal component analysis was used to create the vector graphs, using the Minitab statistics package.

\section{RESULTS AND DISCUSSION}

The principal component analysis was used to determine associations among the evaluated characteristics. The correlations or associations are shown in vector graphs, and the reference variables are EC, ANG, and GS. The principal components are those that show the greatest influence on the reference variables, while secondary components have less influence on the studied traits.

\section{Sex differences}

A high association between ANG and EC was found when male and female Cobb $₫ 500$ broilers were evaluated, showing that birds with poor ANG tend to show stilted EC, while opposite is true (Figure 6). Moreover, there was a high association of ANG and EC with poor GS and moderate association with SPO. Evaluating EC in humans, some authors found a significant correlation between EC and posture, resulting in high rates of spinal problems (Chandler et al., 1990; Cash, 2000; Zucco, 2003; Rivas and Júnior, 2007; Lemos et al., 2007). 
Alves MCF, Almeida Paz ICL, Nääs IA, Garcia RG, Caldara FR, Baldo GAA, Nascimento GR, Amadori MS, Felix GA

Garcia EA, Molino AR

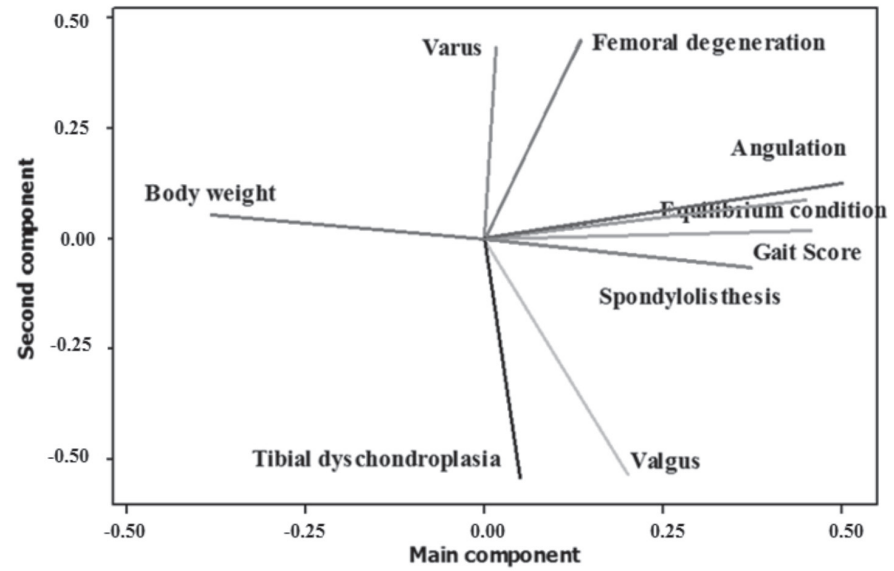

Figure 6 - Association between locomotion pathologies, BW and GS in Cobb $® 500$ males and females.

The variables VAL and VAR and TD and FD were not significantly associated with each other or with the other evaluated traits, as they formed angles between 60 and $90^{\circ}$ to the main component, and were not correlated.

The BW of birds showed strong negative associations with SPO, GS, EC and ANG, that is, body weight is not the main cause of those pathologies, as well as with equilibrium condition and angulation scores. Nevertheless, it does influence these variables.

In both male and female Ross $₫ 308$ broilers, ANG was highly associated with EC, and these traits were moderately associated with GS (Figure 7). Locomotion pathologies did not show any association with gait score in these chickens. Several authors report that the correlation between locomotion disorders and GS is low (Almeida Paz et al., 2010; Cordeiro et al., 2012; Fernandes et al., 2012;). However, when Kestin et al. (1992) proposed this methodology, the purpose was to evaluate and quantify animal welfare. Several authors have tried to find relationships between GS and locomotion problems, as this method is not invasive and estimates gait condition and bird welfare (Garner et al., 2002).

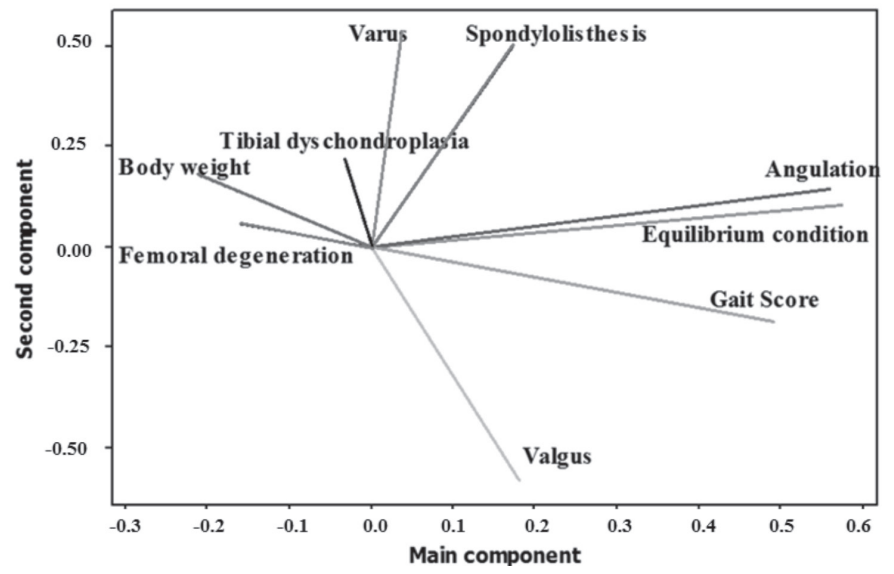

Figure 7 - Association between locomotion pathologies, BW and GS in Ross $® 308$ males and females.
In Ross $₫ 308$ broilers, there was a negative between BW and FD and TD, indicating the higher the body weight, the greater the incidence of these pathologies. These results can be attributed to the fast weight gain of these birds, which are reared for their high muscle accretion, which places an increasing load on the skeleton, consequently resulting in thicker epiphyseal cartilage. These findings may be associated to the fact that reduced blood flow leads to insufficient energy for chondrocyte differentiation, and consequent inadequate bone calcification (Rath et al., 1998). A moderate to strong negative association was determined between BW and FD, that is, these secondary variables may worsen ANG, EC, and GS in these birds, which allows inferring that broilers with FD present walking difficulty and their equilibrium is compromised.

\section{Genetic strain differences}

When comparing the males of the evaluated commercial strains (Cobb $₫ 500$ and Ross $® 308)$, gait score was moderately associated with EC, that is, not all chickens with gait problems had compromised balance. Additionally, EC showed moderate association with ANG (Figure 8). Birds with compromised angulation (prostrated posture) were more likely to have SPO, as the inadequate posture of these birds may allow the slippage of thoracic vertebrae when one vertebra moves over another.

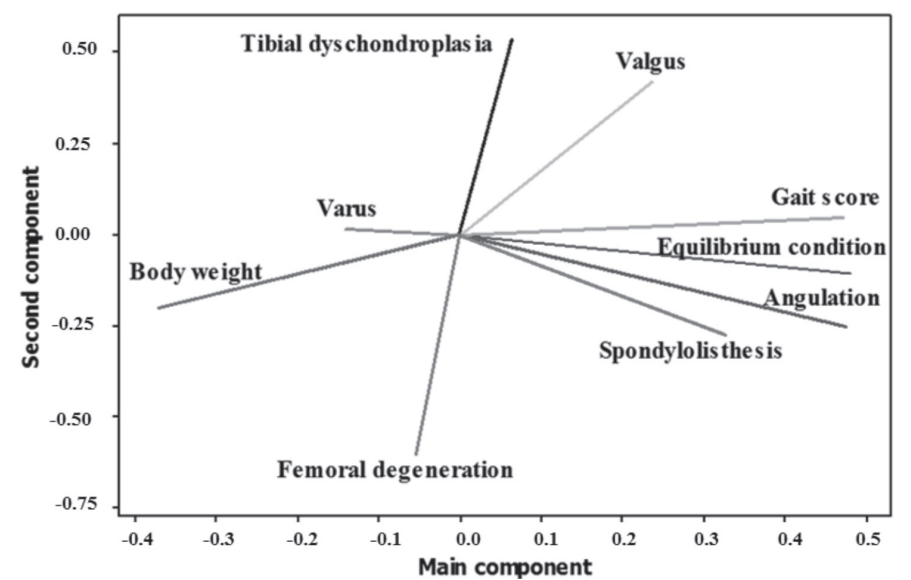

Figure 8 - Association between locomotion pathologies, BW and GS in Cobb® 500 and Ross $\circledast 308$ males.

Locomotion pathologies were not significantly associated. However, there was a moderate negative association of BW and VAR with the reference variables, i.e., chickens suffering from VAR may display gait difficulties.

The parameters evaluated in the vector graph for females of the strains under study (Cobb®500 and Ross ${ }^{\circledR 308)}$ showed similar behavior as in males. 
Alves MCF, Almeida Paz ICL, Nääs IA, Garcia RG, Caldara FR, Baldo GAA, Nascimento GR, Amadori MS, Felix GA, Garcia EA, Molino AR
Equilibrium Condition during Locomotion and Gait in Broiler Chickens
However, a high association between EC and ANG was detected, confirming the hypothesis that the birds suffer due to incorrect posture and show stilted EC (Figure 9). A moderate association was also observed between ANG and GS, while gait score presented low association with SPO. This may be explained by the fact that the GS methodology stimulates birds to walk, and that they walk regardless of any discomfort they may be suffering.

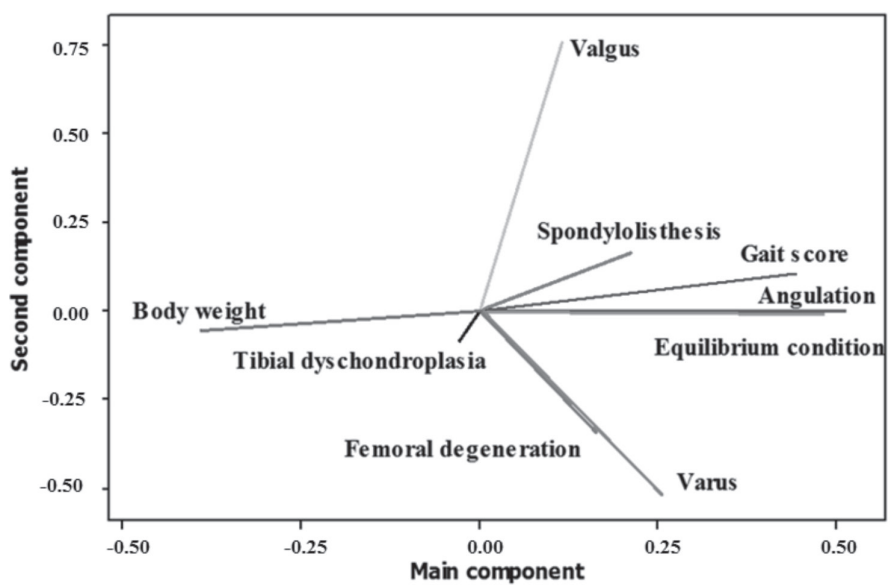

Figure 9 - Association between locomotion pathologies, BW and GS in females of strains $\mathrm{Cobb} \circledast 500$ and Ross $₫ 308$.

Moreover, a moderate association between FD and VAR was observed. Chickens with high FD scores suffered from crooked legs. It is known that there is an increase in angular deformities and in the incidence of locomotion pathologies in general in broilers with higher growth rates (Paixão et al., 2007). The discomfort caused by FD is perhaps compensated by a posture that favors the onset of VAR.

Another contrast is that the BW of females of the different strains presented similar behavior as that of males of the different strains, confirming body broiler weight can play a secondary role in the worsening of GS, ANG, and EC. Also, a higher association among GS, CE, and ANG were obtained in females compared with males. This is related to the fact that males have larger muscle and bone structures, which makes them stronger and with better EC, resulting in less interference of body weight on their ANG.

\section{CONCLUSION}

Gait score showed low correlation with locomotion problems and, therefore, it is not a good indicator of locomotor diseases. On the other hand, angulation and equilibrium condition presented moderate to the high correlation with locomotion problems, and consequently, are better indicators of locomotor diseases than gait score, which is possibly more related to EC and body posture than to bone pathologies.

The evaluation of equilibrium condition and angulation through images may be time-consuming. However, the methodology proved to be a useful tool to assess how broilers walk.

\section{REFERENCES}

ABPA - Associação Brasileira de Proteína Animal. Norma técnica de produção integrada de 303 frango [cited 2014 jan]. São Paulo: União Brasileira de Avicultura; 2014. Available from: http://www.ubabef. com.br/files/publicacoes/8ca705e70f0cb110ae3aed67d29c8842.pdf

Almeida Paz ICL, Garcia RG, Bernardi R, Nääs IA, Caldara FR, Freitas LW, et al. Selecting appropriate bedding to reduce locomotion problems in broilers. Brazilian Journal of Poultry Science 2010;12:189-195.

Almeida Paz ICL. Problemas locomotores e técnicas de mensuração. Anais da Conferência FACTA 2008 de Ciência e Tecnologia Avícolas; 2008; Santos, São Paulo. Brasil. p.128-137.

Almeida Paz ICL, Mendes AA, Takita TS. Comparison of techniques for tibial dyschondroplasia assessment in broiler chickens. Brazilian Journal of Poultry Science 2005;7:27-31.

Broom DM, Molento CFM. Bem-estar animal: conceitos e questões relacionadas - revisão. Archives of Veterinary Science 2004;9(2):1-11.

Cash MS. Neurologia para fisioterapeutas. São Paulo: Premier; 2000. p.402.

Chandler JM, Duncan PW, Studenski SA. Balance performance on the postural stress test: comparison of young adults, healthy, elderly, and fallers. Physical Therapy Journal 1990;70:410-415.

Cordeiro AFS, Baracho MS, Nääs IA, Nascimento GR. Uso de mineração de dados para identificação de fatores que influenciam o grau de lesões de perna em frangos de corte. Engenharia Agrícola 2012;32(4):642649 .

Cordeiro AFS, Nääs IA, Salgado DD. Field evaluation of broiler gait score using different sampling methods. Brazilian Journal of Poultry Science 2009;11:149-154.

Fernandes BCS, Martins MRFB, Mendes AA, Almeida Paz ICL, Komiyama CM, Milbradt EL. Problemas locomotores em frangos de corte e sua relação com gait score. Revista Brasileira de Zootecnia 2012;33(5):128135.

Garner JP, Falcone C, Wakenell P, Martin M, Mench JA. Reliability and validity of a modified gait scoring system and its use in assessing tibial dyschondroplasia in broilers. British Poultry Science 2002;43:355-363.

Goliomytis M, Panopoulou E, Rogdakis E. Growth curves for body weight and major component parts, feed consumption, and mortality of male broiler chickens raised to maturity. Poultry Science 2003;82:1061-1068.

Julian RJ. Valgus-varus deformity of the intertarsal joint in broiler chickens. The Canadian Veterinary Journal 1984;25:254-258.

Kestin SC, Knowles TG, Tinch AE, Gregory NE. Prevalence of leg weakness in broiler chickens and its relationship with genotype. Veterinary Record 1992;131:190-194.

Knowles TG, Broom DM. Limb bone strength and movement in laying hens from different housing systems. Veterinay Record 1990;126:354- 356.

Lemos LFC, Mann L, Pranke GI, Teixeira CS, Rossi AG, Mota CB. Investigação do equilíbrio estático em praticantes de canoagem velocidade. Anais 
Alves MCF, Almeida Paz ICL, Nääs IA,

Garcia RG, Caldara FR, Baldo GAA,

Nascimento GR, Amadori MS, Felix GA,

Garcia EA, Molino AR

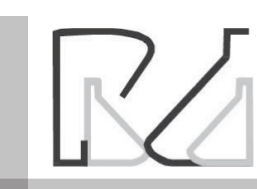

Equilibrium Condition during Locomotion and Gait in Broiler Chickens do $12^{\circ}$ Congresso Brasileiro de Biomecânica; 2007; Rio Claro, São Paulo. Brasil. p. 6.

Nääs IA. Princípios de bem-estar animal e sua aplicação na cadeia avícola [palestra]. O Biológico 2008;70(2):105-106.

Paixão TA, Ribeiro BRC, Hoerr FJ, Santos RL. Espondilolistese em frango de corte no Brasil. . Brazilian Journal Veterinary Research and Animal Science 2007;59:523-526.

Rath NC, Huff WE, Bayyari GR, Bolog JM. Cell death in avian tibial dyschondroplasia. Avian Diseases 1998;42:72-79.
Rivas RC, Andries Júnior O. O dimorfismo sexual e suas implicações no rendimento e planejamento do esporte feminino. Movimento e Percepção 2007;7(10):126-148.

SAS. SAS/STAT user's guide. Version 9. Cary: SAS Institute; 2004.

Waldenstedt L. Nutritional factors of importance for optimal leg health in broilers: A review. Anim Feed Science and Technology 2006;126:291307.

Zucco F. A reabilitação vestibular no idoso. Brazilian Journal of Physical Therapy 2003;7:35-37 
